\title{
Sustaining safety across organizational boundaries: a qualitative study exploring how interorganizational complexity is managed on a petroleum-producing installation
}

\author{
Vibeke Milch $^{1}\left[\right.$ [D $\cdot$ Karin Laumann ${ }^{1}$ \\ Received: 19 September 2017 / Accepted: 10 January 2018 / Published online: 18 January 2018 \\ (c) The Author(s) 2018. This article is an open access publication
}

\begin{abstract}
A qualitative study was undertaken to explore how interorganizational complexity is managed on a petroleum-producing installation. Fourteen semi-structured interviews were conducted. Data were analysed by means of thematic analysis. Longterm organizational relations, management's role in the field and worker involvement appear to facilitate high-quality work relations which, along with similar safety practices and philosophies across companies, appear to foster commitment to mutual operational goals and contribute to an open environment in which employees were inclined to report errors and problems. Still, due to the vast number of companies involved and the vast amount of information, coordinating work processes among companies was regarded as a constant challenge. Moreover, variations in experience among sharp-end workers from sub-contractor companies in periods of high activity and marked fluctuations were identified as a challenge. The quality of interorganizational work relations appears to have important implications for safety performance in this context, indicating that high-quality work relations across collaborating companies constitute an important component for achieving and sustaining safety. As research addressing relational factors in safety research to date has been sparse, more research is needed to further explore the safety functions of high-quality work relations. Theoretically, the current study contributes to extend the high-reliability organizations framework by highlighting the role of high-quality work relations as an element for achieving mindfulness.
\end{abstract}

Keywords Interorganizational complexity $\cdot$ High-reliability organizations $\cdot$ Petroleum industry

\section{Introduction}

The development towards more technologically advanced and complex organizations embodies one of the chief concerns in the safety field (Dekker 2012; Grøtan et al. 2010; Le Coze 2005; Rasmussen 1997). Increased system complexity involves increased possibilities of ways that technology, systems and people can interact, thus limiting our ability to fully comprehend work processes (Hollnagel 2012; Leveson 2011; Perrow 1984). Therefore, complexity represents one of the major challenges for being able to design safe systems

Vibeke Milch

Vibeke.milch@ntnu.no

Karin Laumann

Karin.laumann@ntnu.no

1 Department of Psychology, Norwegian University of Science and Technology, 7491 Trondheim, Norway and being able to comprehend signals of vulnerability in the system before they escalate into situations beyond recovery and result in catastrophic accidents.

A defining trend in modern safety-critical industries such as petroleum, nuclear power and aviation is the increased dependence on contractors and service companies to perform operations. Such companies can be incorporated in different ways with varying degrees of involvement, often delivering tools or pieces of equipment, specialized technology or specific services (Beale 2003). Involvement of multiple organizations involves an increase in complexity because work processes require collaboration and coordination among a number of different organizations with different specializations (Sujan et al. 2015), different areas of responsibility (Cedergren 2013) and different safety cultures (Johnsen et al. 2006). Furthermore, such organizational diversity may also entail greater workforce fluctuation due to short-term contracts and employees who are not readily familiar with each other nor the environment in which they 
perform their work tasks (Clarke 2003). Arguably, development towards increased interorganizational complexity implies several alterations to how the work processes are structured and performed that may have implications for safety.

Interorganizational complexity has been shown to give rise to issues associated with the occurrence of major accident scenarios and incidents with major accident potential across an array of safety-critical industries. Examples include the NASA accidents involving Challenger (Vaughan 1990) and Columbia (Garner 2006), UK railway accidents Bexley (HM Railway Inspectorate 1999) and Hatfield (Office of Rail Regulation 2006), the Montara oil spill in 2009 (Montara Commission of Inquiry 2010) and the Deepwater Horizon accident (National Commission on the BP Deepwater Horizon Oil Spill and Offshore Drilling 2011; Tinmannsvik et al. 2011). Recurring issues among these incidents were related to communication and coordination of interfaces across organizations and lack of shared operational focus. These examples clearly illustrate that the involvement of multiple companies places greater demands on the communication and management of interfaces between organizations in operations.

Milch and Laumann (2016) conducted a study where empirical literature addressing interorganizational safety issues in safety-critical contexts was examined. Safety issues fell into four categories: issues arising from economic pressures among organizations; issues associated with problems concerning organizing and coordinating operational activity across organizational interfaces; issues associated with lack of competence and experience among employees from different organizations; and issues associated with organizational differences among companies. An overarching trend in the literature was the absence of shared attention among various companies to operational processes and safety management. Issues such as lack of shared responsibility for safety management (e.g. Jeffcott et al. 2006), distrust among employees across companies (e.g. Collinson 1999), fragmented decision-making processes (e.g. Cedergren 2013), confusions of responsibilities among companies (e.g. Mayhew et al. 1997) and safety/production trade-offs (e.g. Gomes et al. 2009) contribute to a narrow operational focus where employees from various companies are largely concerned with their own tasks and responsibilities, neglecting the operation as a whole. In turn, such issues can lead to elevated risk of major accident due to their potential to undermine the ability of the system to identify and comprehend risk signals.

Generally, the literature addressing the link between interorganizational complexity and safety has been sparse, and the majority of these studies have largely focused on factors that contribute to accidents and safety problems. However, less attention has been devoted to understand mechanisms by which safety is achieved across organizational interfaces. Observing how interorganizational complexity is a growing tendency in safety-critical industries, and the likelihood of organizations becoming increasingly complex in future, there is a need to better understand safety challenges as well as practices that promote safety across organizational boundaries.

The aim of the present study is to gain a better understanding of how interorganizational complexity is managed on a petroleum-producing installation. The paper presents data from a qualitative study in the context of a petroleum drilling operation. The paper is part of a larger project where the overarching objective is to obtain new knowledge concerning safety challenges due to interorganizational complexity in drilling and well operations, and how interorganizational complexity is related to major accident risk. The following research questions are posed: What safety challenges arise from interorganizational complexity? What practices can be identified that help manage interorganizational complexity?

\subsection{Safety in complex safety-critical systems}

The accelerating technological and organizational changes we have witnessed in modern industries and the rise or complex socio-technical systems have not only pushed performance to new levels, enabling increasingly advanced operations (Hollnagel and Cacciabue 1999), but have also introduced a number of challenges in terms of safety management in safety-critical systems (Rasmussen 1997). Events such as Chernobyl, the Texas City Refinery explosion and the more recent Deepwater Horizon blowout are all examples of large-scale industrial accidents that have occurred in safety-critical industries that were due to complex interactions between human, technical and organizational failures. The complexity inherent in such systems entails that work processes are fragmented between a number of different actors that operate and make decision independently of each other. Consequently, no one person has a complete understanding of what is going on, and the effects of actions, decisions and interactions in the system are harder to predict and understand (Perrow 1984).

Such developments have challenged existing safety approaches and demonstrated a need for approaches that better cope with these challenges (Kirwan 2001; Rasmussen and Svedung 2000). In the last two decades, there has been a gradual shift in safety thinking, from a predominant focus on the effect of actions made by people in close contact with the system, to a realization that more remote influences in the organization have significant implications for safety. Contributions such as Turner's theory of Man-made disasters (Turner 1978) and Reason's Swiss Cheese-model (Reason 1997) have been important in this regard, highlighting the 
role of latent conditions in the development of large-scale industrial accidents. These developments represent important contributions to the safety field and have led to a better understanding of challenges related to safety management within complex modern organizations. However, the primarily focus in these theories, and in current safety thinking in general, is on safety reducing processes that lead to adverse events, and strategies to prevent such processes. Hence, these theories say less about processes that contribute to safety within contexts characterized by high complexity.

Due to the immense pace with which society is changing, safety management in complex systems requires that organizations are able to actively cope with uncertainty and fluctuations and constantly adapt to the demands and pressures within their environments (Rasmussen 1997; Kontogiannis 2010). In this regard, there is a growing consensus that human and organizational capabilities within the system represent crucial safety-promoting functions that enable successful adaption (Hollnagel 2014; Weick and Sutcliffe 2007, 2015). Accordingly, in order to understand safety in complex systems, it is important to look into the mechanisms by which successful safety management is achieved, in addition to looking into the mechanisms behind accidents and adverse outcomes (Hollnagel 2014).

\subsection{High-reliability organizations}

One strand of research that is relevant in this regard is that of high-reliability organizations (HRO). HRO research has been concerned with understanding why some types of complex safety-critical organizations, despite operating in trying environments in which the potential for errors is omnipresent, seem to maintain high levels of safety performance (La Porte and Roberts 1998; Roberts 1990; Rochlin et al. 1998; Schulman 1993). Examples of HROs include nuclear power plants, air traffic control and nuclear-powered aircraft carriers, among others. These studies imply that HROs have certain characteristics and employ certain practices that enable them to effectively discover and respond to disturbances, thereby achieving sustained reliable safety performance. This includes, among others, flexible decision-making in the face of critical situations (Rochlin et al. 1998; Roberts 1990), the ability to take advantage of diverse viewpoints in the organization (Roberts and Rousseau 1989; Schulman 1993), redundant safety structures and backup systems (Schulman 1993), a culture of shared norms and values, which is socialized to new members (Roberts et al. 1994; Weick 1987), and interrelated communicational practices (Weick and Roberts 1993),

Despite having enjoyed substantial popularity, particularly among practitioners in the industrial and healthcare sectors, the HRO perspective has also been criticized on several points. In particular, the lack of a clear definition of the term HRO, as well as the lack of precise defining criteria, is problematic in the sense that there are really no ways of telling HROs from non-HROs, making it difficult to identify an HRO in the first place (Hopkins 2007, 2014). However, Weick and Sutcliffe's later conceptualization of HRO (Weick et al. 2008; Weick and Sutcliffe 2007, 2015) avoids some of these issues by focusing on organizational processes that organizations may employ to varying degrees. Seen in this light, the HRO concept has become more fluent and is reflected more as an ideal on a spectrum, instead of an either/or dichotomy (Hopkins 2007, 2014).

Through their comprehensive review of HRO literature, Weick et al. (2008) identified a set of strategies that the organizations employ, which in combination enable a state of collective mindfulness. These were: preoccupation with failure, avoiding simplification, sensitivity towards operations, committing to resilience and deferring to experts in critical situations. The authors assert that the success of HROs is ascribable to a sustained state of mindfulness, which allow them to identify and manage unexpected situations before they result in uncontrollable circumstances (Weick and Sutcliffe 2007, 2015; Weick et al. 2008). In other words, it is the stability of the cognitive infrastructure that is mindfulness, paired with a continuous capacity to adapt to changing circumstances, that creates reliable performance.

While the HRO literature has been concerned with complex organizational systems, some of which characterized by interorganizational complexity (e.g. Schulman 1993), limited attention has been devoted to the interorganizational aspects of such systems. Accordingly, little is known about practices that contribute to sustained reliable safety performance across multiple companies. Because interorganizational complexity seems to entail certain unique challenges, there may also be other mechanisms by which safety is sustained in such contexts.

\section{Method}

With regard to the inherent complexity of the phenomenon of interest, and the aim of the current study, a qualitative approach was selected. Qualitative inquiry offers the opportunity for detailed investigation of factors influencing safety within the natural context, while capturing the complexity of the drilling operation (Patton 2014; Silverman 2006). Moreover, with regard to the explorative nature of the study and the scarcity of extant empirical research in this area, a qualitative approach is beneficial because it offers an avenue by which new in-depth knowledge can be obtained.

In qualitative inquiry, making explicit ones philosophical stance is important to ensure transparency (Meyrick 2006). Philosophical framework has important implications for the research focus and design, as well as the interpretations of 
Table 1 Overview of informants

\begin{tabular}{llclll}
\hline Informant & Gender & $\begin{array}{l}\text { Seniority (years in } \\
\text { company) }\end{array}$ & Location & Affiliation & Type of position \\
\hline 1 & M & $3-5$ & Offshore & Rig company & Sharp-end \\
2 & M & $0-2$ & Offshore & Operator company & Management \\
3 & M & $3-5$ & Offshore & Rig company & Management \\
4 & M & $3-5$ & Offshore & Rig company & Management \\
5 & M & $3-5$ & Offshore & Contractor & Sharp-end \\
6 & M & $3-5$ & Offshore & Rig company & Sharp-end \\
7 & M & $3-5$ & Offshore & Rig company & Sharp-end \\
8 & M & $3-5$ & Offshore & Operator company & Management \\
9 & M & $0-2$ & Offshore & Sub-contractor & Sharp-end \\
10 & M & $3-5$ & Offshore & Rig company & Sharp-end \\
11 & F & $11-15$ & Onshore & Operator company & Management \\
12 & M & $6-10$ & Onshore & Operator company & HSE \\
13 & M & $0-2$ & Onshore & Operator company & Contracts \\
14 & M & $6-10$ & Onshore & Operator company & Management \\
\hline
\end{tabular}

findings. In this paper, the researchers ascribe to the postpositivistic paradigm underpinned by an ontology assuming the existence of an objective and observable reality that is only imperfectly and partially apprehendable (Guba and Lincoln 1994). From this perspective, research can never be truly objective and value-free, and it is acknowledged that the research process always to some extent will be influenced by the researcher and the methods applied. Nonetheless, with rigorous and systematic methods, the notion is that it is possible to tap into reality and gain knowledge with pragmatic value beyond the specific context.

\subsection{Subject}

The current study was conducted in the context of an ongoing offshore drilling operation on an offshore installation in the North Sea, involving offshore workers from different companies with various operational roles in the operation. The Norwegian petroleum industry was chosen because it provides an interesting context of study for several reasons. Firstly, operations are interorganizationally complex in that the work requires collaboration among a number of specialized organizations. Secondly, the petroleum industry is a safety-critical industry in which operations involve the use of hazardous and highly complex technologies, where the environments are challenging and the consequence of errors may be adverse. Thirdly, the Norwegian petroleum industry demonstrates a strong focus on safety. World leading performance in health, safety and environment (HSE) is a government stated goal for the petroleum industry (Ministry of Labour and Social Inclusion 2005, p. 11). Accordingly, it provides an interesting context in which to explore both safety challenges as well as practices that help manage interorganizational complexity within a safety-critical industry.

\subsection{Participants}

A purposeful sampling strategy was employed (Patton 2014). This means that selection of participants was guided by the research question and aim of the study. A central sample criterion was to obtain a broad sample reflecting variation in organizational affiliation and operational roles. Accordingly, it was desirable to include employees from different companies involved in the operation, people working onshore as well as offshore, and employees representing both executive roles as well as employees in the sharp-end interacting closely with operational processes.

In order to identify informants, information about the various operational roles was obtained from the operator company. Contact was made directly with each informant, and informed consent was obtained before each interview. The sample includes four onshore and ten offshore employees. In the offshore segment, all informants were male. The onshore segment includes one female, while the remaining informants were male. With regard to affiliation, the sample includes both managers and sharp-end workers representing the operator company, the rig company, one contractor company and one sub-contractor company. ${ }^{1}$ An overview of informants is presented in Table 1 .

\subsection{Procedure}

Fourteen in-depth, semi-structured interviews (Kvale 2008) were administered with onshore and offshore personnel.

\footnotetext{
${ }^{1}$ The functions and organization of companies in the drilling operation are described in more detail in "research findings" under "context".
} 
All interviews were executed face to face, lasting between $40 \mathrm{~min}$ and $1 \mathrm{~h}$, and recorded by means of an audio recorder. Onshore, interviews were conducted in a confined meeting room during the participants' normal work hours. Offshore, interviews were completed in various meeting rooms on the rig during participants' normal shift hours. The interviews followed a semi-structured guide adapted to the individual roles and affiliations of the informants. Open questions were organized around certain pre-established thematic areas; however, the interview guide functioned more as a guideline than a rigid protocol. Given the explorative nature of the study, emphasis was placed on maintaining a flexible enough interview structure to enable informants to introduce new topics in the interview situation in addition to the predefined topics. Questions involved basic background information followed by questions concerning participants' roles in the ongoing operation, typical work tasks, involvement with co-workers from other companies, perceptions of working interorganizationally and, finally, safety and accident reporting. Examples of questions include: Can you describe your previous shift from start to finish? Can you describe a situation in which you have worked with employees from companies other than your own? How do you experience working with employees from other companies than the one you are hired in? Do you see any challenges with there being multiple organizations involved in terms of safety? An example of interview guides used in the study is found in appendix ("Appendix 1").

When developing the interview guide, the researcher's focus along with theoretical perspective is elements which greatly influence what is emphasized and also, inevitably what is uncovered in interviews. Hence, such details are relevant in order for the reader to evaluate the work. Interview guides were developed based on previous findings from review of the literature on interorganizational complexity and safety (Milch and Laumann 2016). Additionally, since our point of departure concerned organizational safety and major accidents, the theoretical perspectives of Reason (1997) and HRO (Weick and Sutcliffe 2007, 2015; Weick et al. 2008) were also used as a source of inspiration in developing questions. Based on this backdrop, the initial interview guides had a strong focus on safety challenges. During the process of collecting data, however, informants generally talked more about practices that contributed to maintain safety across companies. In response, interview guides were adapted to facilitate these topics in the remaining interviews.

In order to better understand the nature and organizational aspects of the work and the context, observations were conducted onshore and offshore. Furthermore, relevant operational documents were examined. Activities observed involved onshore rig meetings along with central operational activities offshore such as drilling, drilling deck activities and control room activities. Offshore observations were conducted over a 5-day period. The observations and document analysis were conducted to gain a better understanding of the work with a particular focus on interorganizational interactions in the operation. It should be noted that the observation data and documents were not subject to coding, but were used to inform the context and provide a supportive framework for analysis. In accordance with normal ethical conduct, the project was notified to NSD (Norwegian Social Science Data Service).

\subsection{Data analysis}

The interview material was transcribed, and data were analysed by means of inductive thematic analysis (Braun and Clarke 2006), the aim of which is to identify patterns across a given data set. The method was chosen for several reasons. To begin with, thematic analysis is regarded as particularly suitable for analysing underexplored research areas in which pre-established knowledge is scarce or unavailable. Moreover, the method is theoretically flexible and can be adapted to fit most research questions, at the same time as it allows for a systematic and rigorous analysis. Following the guideline described by Braun and Clarke (2006), familiarization was achieved by reading and re-reading the content. The next stage involved a coding process in which the material was systematically examined line by line and each segment assigned a descriptive label or code. This part of the analysis was completed using the software program NVivo 11. After the material was coded, the initial codes were compared and sorted into rudimentary categories. Categorization at this stage was relatively crude. Content of codes and developing themes were then scrutinized and compared, deviations sought and developing themes revised accordingly. In the final stage, themes were reviewed and organized. Examples illustrating the coding process are presented in Table 2.

Several steps were taken to ensure the quality of analysis. Audit trail analytical memos and the method of constant comparison were techniques employed to test and track the developing categories. The material was further examined for disconfirming evidence (deviant cases). This is a strategy to test the robustness of the categories (Creswell and Miller 2010); however, no deviant cases were identified. To assess the credibility of analysis, findings were presented to and confirmed by our primary contact in the operator company.

\section{Research findings}

The aim of this paper was to explore how interorganizational complexity is managed on a petroleum-producing installation, in order to gain a better understanding of safety challenges as well as practices that help 


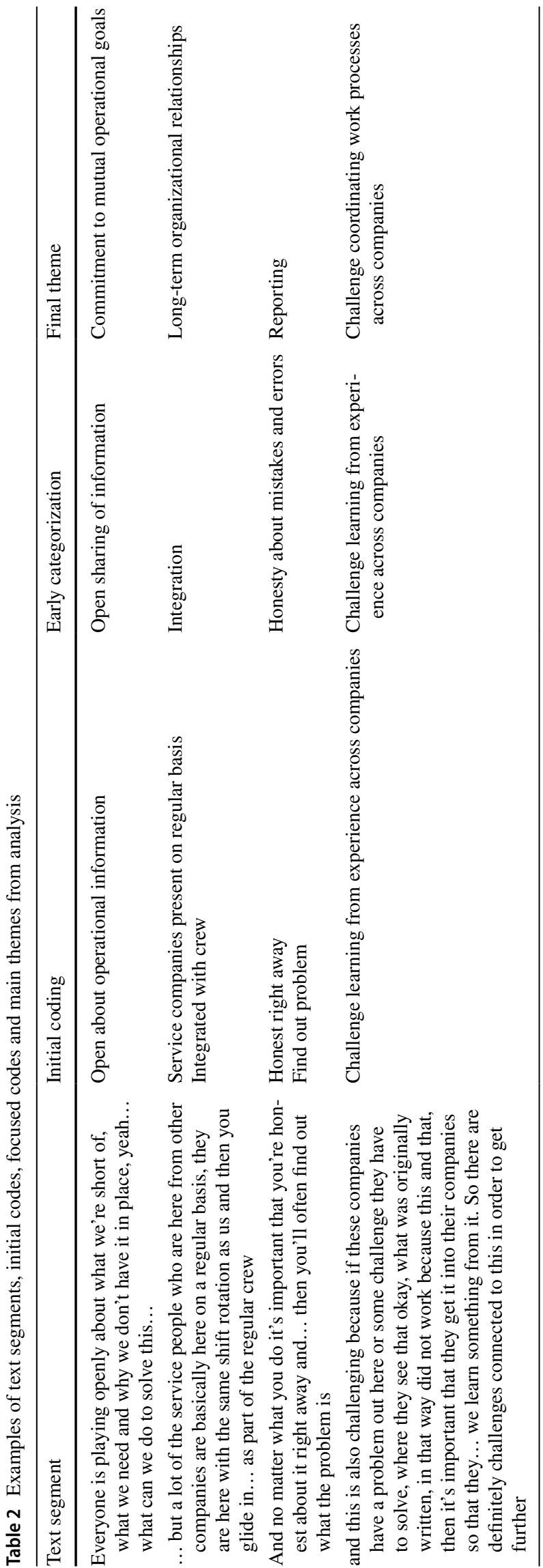

manage interorganizational complexity. Through analysis, two themes were identified which describe safety challenges: challenge coordinating work processes across companies and varying experience among sub-contractors. Moreover, seven themes were identified which describe practices found to help manage interorganizational complexity: long-term organizational relationships; management's role in the field; worker involvement; similar safety practices and philosophies across companies; high-quality work relations; commitment to mutual operational goals; and reporting. Before the research findings are presented in detail, a description of the context is provided. The context is informed by the observational and interview data, document analysis and literature.

\subsection{Context}

In qualitative research, the particular context in which a research phenomenon occurs is regarded as an integral aspect of the phenomenon of study, referring to the conditions and circumstances to which informants respond and which influence their perceptions and behaviours (Corbin and Strauss 2014). Consequently, the context represents an important framework for understanding the research findings. A thorough account of the context is also important in terms of generalizability, so readers are able to consider to what extent findings may be transferable to other contexts.

The overall context is a drilling operation on a semi-submersible drilling rig situated on the NSC in the North Sea. The operation represents a cooperation between a large number of specialized companies. The operator company, which is the main actor, manages the overall operation and delivers the drilling programme. The rig company provides the rig and drilling crew and finalizes the drilling programme on behalf of, and in close collaboration with, the operator company. Hired by the operator company are various third-party service companies which provide equipment or specialist services in the well, such as cement, casing and drilling fluids. Also, the rig company employs its own service companies which deliver rig-specific equipment and services such as scaffolding and sub-sea services. Moreover, various subcontractors are also hired by the service companies, supplying additional specialist services and equipment. Arguably, the interorganizational picture is quite complex. An illustration of the interorganizational structure is provided in Fig. 1.

The activity surrounding the operation happens both onshore and offshore, representing fundamentally different physical and psychosocial arenas. Onshore, activities are conceptualized, planned and coordinated between companies. Live meetings with the rig and physical meetings with various representatives from the organizations involved are typical daily activities. Offshore activities are executed on a mobile semi-submersible drilling rig on which 




Fig. 1 Illustration of interorganizational structure

the employees both work and live. All operational activity is highly regulated and involves thorough planning both onshore and offshore. Employees normally work 12-h shifts in a rotation of 2 weeks on and 4 weeks off. The 'sharp-end' workers, such as the drilling crew and contractor/sub-contractor employees, spend most of their time out in the field in physical proximity to hazardous processes. Management personnel, or 'blunt-end' workers, spend their work day in meetings with shore-based counterparts, in internal meetings, and supervising the drilling activity from the rig control room and in the field. While the crew from the rig company and employees from the main contractor companies are permanently stationed at the rig, sub-contractor employees who provide less frequently needed services tend to travel between rigs and stay for shorter periods of time.

Another important aspect of the context concerns the national context. From an international point of view, the Norwegian petroleum industry ${ }^{2}$ is considered unique in terms of its safety focus and for how the petroleum activity is regulated based on a tripartite collaboration among employee organizations, unions and the government. In this context, worker participation and co-determination represent core values (Hart 2002). In the last two decades, there has been a strong focus from the government on establishing a sound safety culture in the petroleum industry, which has had noticeable implications for practice and safety performance on the NCS. Another defining feature of the Norwegian safety regime is the high level of cooperation and openness across the operating companies, contractors and suppliers operating on the Norwegian Continental Shelf. 'Working together for safety' and 'Safety forum' are examples of cooperative initiatives aimed towards promoting

\footnotetext{
${ }^{2}$ For a description of the safety regime in the Norwegian petroleum industry, see Tharaldsen (2011).
}

safety in the industry by establishing dialogue across companies about safety issues. Here, the companies share information, experiences and lessons learnt with each other.

\subsection{Practices that help manage interorganizational complexity}

Since the data reflect a stronger representation of practices found to help manage interorganizational complexity, these will be presented first. Seven themes were identified: longterm organizational relationships; management's role in the field; worker involvement; similar safety practices and philosophies across companies; high-quality work relations; commitment to mutual operational goals; and reporting. The themes were found to be situated at different levels and were also found to be considerably interconnected. For this reason, this section of the findings is illustrated in a thematic map.

Figure 2 models themes identified as practices that help manage interorganizational complexity and the relationship between the themes. In the model, long-term organizational relationships, worker involvement, management's role in the field, and similar safety practices and philosophies across companies are themes which represent organizational practices related to the operational context. The former three were found to be conducive to high-quality work relations, thereby reflecting interpersonal practices. In turn, highquality work relations, along with similar safety practices and philosophies across companies, were found to promote commitment to mutual operational goals among the companies and reporting, representing behavioural aspects in the model. In the following, a detailed description of the model will be provided. Moreover, for the purpose of providing transparency to the analysis, an appendix containing interview quotes to illustrate the themes identified in the 




Fig. 2 Practices that help manage interorganizational complexity

study is included (Appendices Tables 3, 4, 5). The quotes are referenced in the text by number.

\subsubsection{Long-term organizational relationships}

The rig was hired by the operator company for a 12-month period; however, the main service companies were engaged on long-term contracts spanning several years. Many of these contractors, who specialize in delivering services and custom equipment to this particular oil field, are engaged in long-term cooperation with the operator company. The fact that the main contractors were engaged through longterm contracts seemed to help streamline organizational processes and clarify roles and responsibilities among the companies involved. These companies have become closely aligned after working on the same drilling projects over long periods of time and have grown familiar with each other's systems and practices. Employees from both the rig company and the operator company said that the two companies had worked together for such a long time that the working relationship between the companies was quite worked-in and well-functioning, reporting few conflicts in day-to-day operations (quotes 1-3). As one rig-company informant put it: Now we've been working for [the operator company] for a longer period and then it's... I think they are starting to trust that we are doing what we're supposed to you know. Playing with open cards and having a good trust relation between costumer and contractor.

Although semi-submersible drilling rigs share many common features in terms of technology and equipment, 
there are still large variations across rigs. As such, informants argued that it generally takes a few visits to the rig to become familiar with the systems and adapt to local variations. The stability of having the same people involved was seen as something that had several positive consequences. Offshore, employees from the main contractors were permanently stationed on the rig throughout the contractual period for which the companies were engaged and had the same shift rotation as the permanent workers. This was regarded as something which contributed to the reduced number of operational challenges due to better integration with the rig crew, as well as contractors becoming familiar with the local work environment and the systems and equipment on the rig (quotes 4-7). A rig-company employee said: Many of the service people that come here from other companies are here on a pretty regular basis, they are here in the same rotation as us and then you glide in like one of the regular crew.

Onshore, it was implied that having the same company representatives following up the operation contributed to better group cohesion and a more open climate for discussions.

The analysis suggests that long-term organizational relationships contribute to high-quality work relations because employees from the main contributing companies work together on a permanent basis and, as a result, become better acquainted and develop stronger collaborative bonds with one another. Particularly for sub-contractor and contractor personnel, being permanently involved in the work environment and in the drilling project also appears to induce a stronger commitment to mutual operational goals.

\subsubsection{Management's role in the field}

Another important theme that emerged from the analysis concerned management's role in the field. Informants with management responsibilities offshore, from the operator company and the rig company, said that being present 'in the field' and being in proximity to the operational activities represented one of the most important aspects of their work. Among the informants with management responsibilities, it was often stated they tried to spend as much time as they could outside. One informant even said that it was out in the field that 'the real work happened' and where the key safety work was done. It was expressed that it was by being physically present in the field that managers were best able to get a sense of what was going on, supervise the ongoing activity, correct problems, and motivate and support employees (quotes 8-10). In this sense, managers' active role in the field appears to have important functions in terms of coordinating the work processes, creating mutual understanding among involved personnel and maintaining operational oversight. Another aspect that was emphasized was that being present in the field was important in terms of establishing contact with the various personnel at the sharp-end. Interacting and spending time in the field with the sharp-end workers was described as essential for establishing trust, which in turn was regarded as a crucial element for getting sharp-end workers from the various companies to speak up concerning safety matters (quotes 11 and 12). One of the managers stated: We are out here as a part of the crew, and we get a lot of contact if we build trust, then they will also be inclined to share challenges, share good and bad things. Still, managers expressed that finding the right balance in terms of the time spent planning the work and time spent out in the field supervising the work was difficult, and with growing amounts of paperwork, finding enough time to spend in the field was a challenge (quote 13).

Through their role and involvement, managers play an important part in coordinating and supervising the work processes in the operation by interacting and working closely with those at the sharp-end of operations. As such, management's role in the field seems to be conducive to high-quality work relations with employees at the sharp-end. The presence of high-quality work relations between managers and sharp-end workers in turn seems to be important both to increase commitment to mutual operational goals among those involved through encouragement and support and to promote reporting behaviour through trust.

\subsubsection{Worker involvement}

Due to the complex nature of the operation and the level of specialization among employees and companies, informants indicated that maintaining a complete picture of the operation required obtaining diverse viewpoints and maintaining an open environment in which every employee can share safety-related information and participate in discussions (quotes 14 and 15). Everybody was expected to participate in activities pertaining to safety, voice safety concerns, report errors and intervene in cases of observed unsafe behaviour, regardless of professional rank or organizational affiliation. The informants believed that the development towards a stronger focus on worker involvement and deemphasizing of top-down authority in the industry represented a step in the right direction in terms of achieving a high level of safety. Sharp-end workers in particular frequently talked about the cultural change in the industry which they said had led to a greater focus on independent thinking, less focus on assigning blame, and more horizontal and constructive forms of communication compared to earlier. The change was seen as something which had resulted in more openness among employees and across companies (quote 16).

Several sharp-end informants implied that the cultural change in the industry had also served to reduce the 
distance between the operator company management and the sharp-end workers. Due to the hierarchical position of the operator company in terms of being in charge of the operation, talking to the operator management was described as something which normally involved a certain threshold. However, an open-door policy and the fact that the authoritative role associated with professional rank was downplayed were seen as elements that contributed to reducing this distance. A sharp-end informant said: It's equal, even though... you do have your bosses, when they say jump, you have to jump, but they talk to you like you're a normal man in the street. I think that's very important, that people feel a little included.

Several sharp-end informants contrasted their experiences on the rig with previous experience on rigs abroad and expressed their belief that the enactment of a much stricter hierarchical system which was common on rigs abroad such as in the UK and the US served to undermine communication and openness among sharp-end workers and operator management, which stood in contrast to the way things were done on the current rig (quote 18).

The analysis indicates that worker involvement through an increased focus on independent thinking and employee participation contributes to strengthen employees' commitment to mutual goals in the operation. Moreover, worker involvement also seems to contribute to better cooperation between employees across various companies and across organizational levels and to promote high-quality work relations in the operation which, in turn, were found to create a more open climate for reporting errors and mistakes.

\subsubsection{Similar safety practices and philosophies across companies}

Safety practices and philosophies were described as quite similar across the main contributing companies. Although each company had its own specific formulations and safety rules, the main philosophy and content was more or less the same (quotes 19-22). Also, the reporting systems were similar across operating companies on the NSC. The informants believed that this had important implications for safety because their work was underpinned by the same safety philosophy and shared perceptions regarding safe operational conduct (quote 23). This can be considered in the light of an increased emphasis on safety in the industry in recent decades, which seems to have brought companies operating on the NCS closer in their safety thinking. Regulatory standards such as $\mathrm{NORSOK}^{3}$ and collaborative initiatives

\footnotetext{
${ }^{3}$ NORSOK is a set of regulatory standards used in operations on the NCS with the intention to, as far as possible, replace company-specific rules and procedures. The standards are based on international standards and are used as regulatory reference in Norwegian petroleum legislation (Standard Norge 2017).
}

such as 'Working together for safety' and 'Safety forum', in which best practices and learnt lessons are shared among companies in the industry, were also mentioned as important arenas which contributed to aligning the safety focus across companies.

Similar safety practices and philosophies across companies appear to contribute to strengthen the commitment to mutual operational goals among those involved in the operation, because there are fewer situations in which incompatibilities among companies may occur and employees from different companies will have similar perceptions concerning safety. Moreover, similar reporting systems and safety focuses also promote better conditions for reporting.

\subsubsection{High-quality work relations}

The attention to relational aspects of the work among informants was a striking tendency in the material. Highquality work relations were identified as the most prominent theme in the analysis. However, while the other themes were more directly identified in the material, this appears to be a more underlying theme throughout the data. The analysis suggests that high-quality work relations are a key element for achieving the level of openness, trust and collaboration necessary for ensuring safe operation across the various companies. In general, employees seem committed to maintaining cooperative work relations. Both onshore and offshore, employees interact a great deal with co-workers from different companies. However, not everyone is well acquainted and develops strong collegial relationships, yet still they work closely in the operation. Because employees do not necessarily know each other well, putting in extra effort to establish good working relationships and interacting well with people are regarded as elementary to maintain well-functioning collaborations. This was evident in the interviews both onshore and offshore, and among both managers and sharp-end workers (quotes 24-27). For example, one of the managers stated: I feel strongly that if you interact well... or if you do your best to interact well with people, then... and look after them, basically. Try and demonstrate that I've god the best interest at heart. Fairly simple human behaviour, really. Not necessarily safety related, but, I tend to think they keep people as safe as they can.

Having good social skills and engaging in friendly and respectful interactions were perceived to be important elements in daily communication and regarded as directly relevant for safety. Sharp-end workers were particularly concerned with the importance of treating colleagues well and expressed the belief that treating each other badly could have profound negative effects on individual performance and safety. A particularly recurring topic in this regard concerned the psychosocial effects of negative forms of communication such as shouting and screaming, which had been 
common practice in the industry in the early days (quotes 28 and 29). This was regarded as a form of communication that had detrimental effects on working relationships, the work climate and safety performance, being generally regarded as a negative thing that reflected unprofessionalism and belonged to the past.

Accordingly, high-quality work relations appear to be a crucial premise for maintaining a well-functioning collaboration among employees from the various companies and seem to contribute to shared commitment to mutual operational goals among those involved because employees become more oriented towards each other when they have developed high-quality relationships. Furthermore, high-quality work relations, creating a general atmosphere conducive to professional and constructive communication, also appear to promote reporting behaviour.

\subsubsection{Commitment to mutual operational goals}

There was a strong commitment to mutual operational goals among the employees in the drilling operation. Informants saw the operation as a team effort where the role of each person was regarded as equally important in order to have a successful and safe operation (quotes 30-33). Furthermore, due to the interdependent nature of the operational activities, the notion of safety for many informants seemed to revolve around the conception of a well-functioning collaboration between personnel involved in the operation. The attitude seemed to be that as long as the cooperation is working, the rest will fall into place.

Because the various companies enter at different stages in the operation to perform their designated part of the job, it was recognized that everybody depended on being handed relevant operational information in order to be able to perform their specific work task. A contractor employee said: Everybody is dependent on each other, particularly in service, where there may be a guy who's sole responsibility is a valve, who's only got the valve, and he's dependent on getting out [on the rig] alone and he's dependent on everybody else in order to cooperate and to know if it fits here or there. And the same with us, we're dependent on having a good collaboration with everyone and be handed information we need. At the same time, we provide the information they need, so it has to work if we are going to be able to deliver an efficient and good product (quote 34).

It was mentioned that many of the contractor companies were rivals outside the operational context, because the same companies normally compete for the same contracts. However, informants expressed that once they found themselves in the same operational context, the competitive element was left out. It was in their common interest to collaborate and share information (quote 35). Furthermore, hiding information or not playing openly was seen as something that could compromise the operation and thus would be counterproductive in terms of achieving mutual operational goals. The collective focus on delivering a safe and successful operation seemed to unify employees from different companies in the operation, and it seems that people are able to regard their own responsibilities and tasks in relation to the bigger operational picture. Several informants also said it was important to help and back each other up, which also applied to employees from other companies (quote 36 ).

Commitment to mutual operational goals and the perception of the operation as a collective endeavour seems to make employees more attuned to each other's roles and responsibilities in the operation, which make employees more inclined to share information and assisting co-workers. Furthermore, this also appears to contribute to a more comprehensive understanding of the operation among those involved, because employees are able to see beyond their specific areas of responsibility.

\subsubsection{Reporting}

Being honest and open about mistakes and errors was a recurring topic among informants. There were several channels through which sharp-end workers could report, either through talking directly to management or handing in observation cards, which is a system found on most rigs operating in the North Sea. Although delivering anonymous observation cards was possible, it was common to hand in observations using one's full name. Sharp-end workers expressed that being honest about mistakes straight away was a better alternative than refraining from reporting or hiding errors. It was recognized that honesty about errors was important in terms of being able to detect potential problems (quotes 37 and 38). A sub-contractor employee said: Well, I don't have anything to gain from keeping things hidden... [operator company] the least so, and the rig company... okey, small things they could probably keep kidden, but their interest is that things work. This view seemed to be strongly related to the way management responded to the feedback. Both executives and sharp-end workers were consistent in that reporting was acclaimed rather than reprimanded. However, hiding or not reporting errors was frowned upon (quotes 39-42). The fact that employees were not sanctioned or told off for reporting mistakes seemed to result in more openness because they did not fear retribution.

\subsection{Safety challenges}

The informants generally saw few challenges with the interorganizational nature of the work that could compromise operational safety. The cooperation among various companies was generally seen as well-functioning, and most challenges described were perceived to be more operational 
challenges than safety critical ones. Two prominent themes were identified: Challenge coordinating work processes among companies and variation in experience among sub-contractors.

\subsubsection{Challenge coordinating work processes among companies}

Maintaining operational oversight was regarded by managers as a constant challenge, and a lot of effort went into coordinating work processes among companies (quotes 43 and 44). One of the onshore managers said: But I think the biggest challenge is ensuring understanding maybe, right. Particularly towards sub-contractors, that we sit on a lot of information and background and history throughout and they come into do a small part of that, that they understand the bigger picture, that is very important. And what influence they have on the big picture, yeah, how they can make a difference. And that is the biggest challenge, that you often can... right, things happen quickly and here... we have all the background information, but it is important to share it so they understand how they fit in and what they can do to make a difference.

One issue in particular was mentioned in this regard: learning from experience. The multitude of companies involved, in combination with the vastness of the information, made it challenging to sufficiently transfer lessons learned throughout the network of these companies. Because companies have different focuses and varying degrees of involvement, ensuring collective learning across companies was regarded as a challenge. Information about previous lessons learned was sometimes lost or forgotten, meaning they sometimes had to 'reinvent the wheel' when encountering similar problems (quote 45).

Another challenge mentioned was related to the complexity of the safety systems. As previously mentioned, managers talked about the way in which the safety systems and practices of the different companies were similar. Still, it was mentioned that each company often had its own sets of specific rules and regulations that came in addition to the standardized regulations (quote 46). The informants saw this as adding to the complexity and creating unnecessary confusion, particularly for service companies travelling between rigs, to know what applied. One of the informants said he thought it would be less difficult if things were more standardized.

\subsubsection{Varying levels of experience among sub-contractors}

The level of competence among employees on the rig was generally considered to be high. People were not hired to work on the rig unless they had been working offshore for more than a year. Furthermore, the operator company strove to get the same people back from those who were travelling between rigs, so they would become familiar with the rig over time. However, with fluctuations in the market and periods of high activity, the level of experience could vary among certain groups of sub-contractors, which some informants saw as a concern. In particular, sub-contractor workers who tend to travel between rigs were regarded as less experienced because they were not necessarily familiar with the local work conditions and some of them had less operational experience compared to those who were on the rig on a permanent basis. An offshore manager said: Of course, more actors demand more of the cooperation. At least when a lot of actors tend to come and go. Another challenge we have seen is that... well, I would really say that up until now the activity has been very high. As such, there has been slightly varying quality and level of knowledge in some of the sub-contractors, that personnel. They tend to have... right, they have limited experience. So it has been a challenge that we have had to focus on and have had to follow them up a lot closer so that the primary control over the well is sustained to put it like that, that it is sustained. So that has been a challenge (quote 47).

One informant said that because sub-contractors were on the rig less frequently, they had less safety training compared to contractor employees who were working on the rig permanently and were involved in all safety-related training on the rig (quote 48). There had also been several incidents that had been linked to the lack of experience and lack of familiarity of the rig among sub-contractor workers.

Onshore, inexperience among new sub-contractor companies was also mentioned. Newly established sub-contractor companies did not always have prior experience within the petroleum industry and were not familiar with the level of safety and the way things were done. One of the onshore informants from the operator company said that they often had to reiterate information and that a lot of work went into following-up representatives from different companies (quote 49), particularly those who were new in the industry.

\section{Discussion}

The aim of the current study was to gain a better understanding of how interorganizational complexity is managed on a petroleum-producing installation. In order to obtain a nuanced picture, we explored safety challenges as well as practices that are regarded as important for achieving safety across organizational boundaries. The following research questions were addressed: What safety challenges arise from interorganizational complexity? What practices can be identified that help manage interorganizational complexity? The discussion is structured as follows: First, a summary of the main findings will be given. After that, findings are compared and discussed 
in the light of previous research and the HRO perspective, representing the study point of departure. Finally, the findings are discussed in the light of relevant empirical literature, placing the study in a broader empirical context.

\subsection{Summary of main findings}

The analysis showed that certain organizational practiceslong-term organizational relationships, worker involvement and management's role in the field-were important for the establishment of high-quality work relations among employees from various companies in the operation. Along with similar safety practices and philosophies across companies, high-quality work relations were found to be central to ensuring operational safety. This is because high-quality work relations contribute to commitment to mutual operational goals among employees from different companies and are central for achieving an environment characterized by openness and trust in which employees are inclined to report errors and voice safety concerns.

The challenges identified largely involved structural conditions. Coordinating work processes among the various companies took a lot of time and effort due to the vast amount of information. In particular, learning from successes and failures, along with complexities due to companyspecific variations in safety standards, was seen as challenge. Another issue concerned varying levels of experience among sub-contractor personnel in certain periods. Informants regarded these issues as mainly operational challenges.

\subsection{Comparing findings with previous research}

In a recent paper, Milch and Laumann (2016) reviewed extant empirical literature addressing interorganizational safety issues in safety-critical industries. Safety issues identified were found to stem from economic pressures among companies, problems with organizing and coordinating operational activity across organizational interfaces, lack of competence and experience in personnel, and organizational differences between companies. In comparing the findings from the current study with the literature review, some of the same issues are found. However, the challenges described in the present study seem to revolve largely around structural conditions. Consistent with the findings from the literature review, challenges with organizing and coordinating operational activities across company interfaces and challenges regarding lack of competence and experience among contractor and sub-contractor personnel are found. Contrary to findings in the literature review, however, issues stemming from economic pressures and organizational differences were not found in the current study. This is potentially connected to the practices identified in the present study.

As previously mentioned, the main issues found in the literature review was the lack of shared focus on operational processes and safety management among various companies performing joint operations (Garner 2006; Jeffcott et al. 2006; Mayhew et al. 1997; Vaughan 1990). In the current study, however, employees from various companies seem to exhibit a broader focus on the operation and a better understanding of each other's roles and responsibilities. This collective orientation seems to be closely linked to the practices identified in the study, implying that certain issues that can arise from interorganizational complexity may be managed through organizational and interpersonal efforts.

Interestingly, apart from collective efforts such as 'Working together for safety' and 'Safety forum', the identified practices that appear to help manage interorganizational complexity do not seem to be deliberate, or reflect explicit strategies to cope with interorganizational complexity. Instead, they seem to be more inherently embedded in the way things are done. Accordingly, they seem to have developed over time as a result of changes in the industry, of which increasing interorganizational complexity has been an essential part.

\subsection{Comparing findings with HRO framework}

In comparing findings from the current study with the HRO principles outlined by Weick and Sutcliffe (Weick et al. 2008; Weick and Sutcliffe 2007, 2015), there are certain overlapping aspects. For example, our findings similarly illuminate the role of experts at the sharp-end. Due to the interdependent nature of the work and the fact that available expertise is fragmented across a vast number of smaller companies, active involvement of sharp-end workers in work processes and their continuous feedback concerning errors and problems is crucial for safe operation. Furthermore, the present study also indicates that shared focus on mutual operational goals among those involved is central to maintaining operational oversight and a high level of safety, which is arguably similar to the concept of mindfulness.

However, our study seems to shed light on different processes contributing to safety compared to the processes identified by Weick and Sutcliffe (Weick et al. 2008; Weick and Sutcliffe 2007, 2015). While mindfulness is conceptualized as the result of cognitive processes shared by the members of the organizations (Weick et al. 2008), the present findings illuminate the role of social processes in achieving reliable performance and safety. Another distinction seems to be the level of explicitness at which the processes operate. While the processes of mindfulness described by Weick et al. (2008) appear to reflect an explicit mindset shared by members, and practices that are actively employed in the organization to maintain reliable performance, the practices identified in the current study on the other hand seem to be more implicit, and not necessarily actively directed towards coping with interorganizational complexity.

High-quality work relations appear to have an important function in terms of promoting trust and openness among 
employees and seem to be central to achieving a well- functioning collaboration among employees from different companies. Furthermore, the presence of high-quality work relations appears to engage employees in safety behaviours such as reporting problems, sharing relevant information and helping co-workers, behavioural factors that have been associated with mindfulness (Weick and Sutcliffe 2007, 2015; Weick et al. 2008). This implies that mindfulness may also be rooted in relational work aspects.

Although the relevance of relational factors such as mutual respect, interpersonal skills and trust has been indicated in HRO literature (Schulman 1993; Weick 1993), such factors have generally been given less attention. However, in a more recent paper, Vogus et al. (2014) argue that mindful organizing is more likely when people engage in prosocial behaviours and are oriented towards others. A possible explanation for relational factors being somewhat neglected might be that the effect of relational factors may be less prominent in organizational contexts in which it is taken for granted that workers are employed by the same company and have the opportunity to develop collegial bonds. It is likely that the relevance of relational factors becomes more distinct in interorganizationally complex contexts, where establishing relational bonds can be more challenging, while the work demands close cooperation among employees who are not necessarily well acquainted. It can be argued that the current study contributes to extending the HRO framework by accentuating the role of high-quality work relations as a key to achieving mindfulness, and by including interorganizational factors which have been given little attention in this area of research.

\subsection{Relational aspects of work in safety research}

While research addressing relational aspects of work in terms of safety has generally been sparse, there is some evidence to suggest that high-quality work relations contribute to safety. Carmeli and Gittell's (2009) study showed that high-quality relationships among employees contribute to improved coordination of work tasks and increase the likelihood of learning from failures. This is because high-quality relationships promote psychological safety; the extent to which employees perceive the level of interpersonal risk to be low enough that they are willing to share information, knowledge or ideas (Edmondson and Lei 2014). Perceived psychological safety contributes to employees perceiving that it is safe to speak up about errors and issues without fear of retribution (Carmeli and Gittell 2009). Thus, psychological safety is also closely related to interpersonal trust (Edmondson and Lei 2014). Similarly, Conchie and Donald (2008) argue that relational aspects such as honesty, concern and care are the most important determinants of the quality of industrial relations because they serve to reduce perceptions of psychological risk, thereby increasing the likelihood of employees engaging in helping behaviour and openly communicating errors or mishaps to others. A study conducted by Mearns and Reader (2008) suggested that perceived support and care from managers were associated with increased safety citizenship behaviours among employees-that is, safety behaviours that exceed regular compliance. Moreover, Nævestad et al. (2007) found that initiatives aimed at promoting relational factors such as care contributed to reducing communication barriers stemming from informal hierarchies among contractor and operator personnel offshore. As such, high-quality work relations may also be important in terms of laying the foundation for more informal arenas in which employees from different companies can discuss safety-related issues. Sujan's (2015) study of hospital professionals suggests that informal arenas provide important contexts in which safety-related information is shared and discussed among managers and peers, which contributed to improved patient safety. These studies support findings from the current study, suggesting that work relations have important implications for safety, while highlighting the need for more research on the link between relational work aspects and safety.

\subsection{Implications}

Several implications for the petroleum industry can be drawn from this study. Most importantly, the current study emphasizes the importance of high-quality work relations as an element that helps managing interorganizational complexity, on both an organizational level and an individual level. For practitioners, giving attention to work relations across companies, and initiatives aimed at promoting high-quality work relations, may be beneficial for achieving high levels of safety by contributing to increased openness and improved cooperation among employees from different companies.

A key element concerns the interactive role of management in the field. Through interacting and working closely with employees at the sharp-end, managers build trust relationships with employees, which induce employees to speak up about safety issues. This is in line with previous research (Hofmann and Morgeson 1999; Kivimäki et al. 1995). Managers have been recognized as playing an important role in terms of shaping safety culture (Reason 1997) and are through to exert both direct and indirect influences on safety behaviours of employees (Flin and Yule 2004). The interactive role of management found in this study is similar to the concept of transformational leadership (Bass 1985), describing leadership behaviours based on trust relations, that encourage employee performance transcending goals of selfinterest towards collective organizational goals. Although studies on transformational leadership in relation to safety are few, there are some studies where transformational leadership behaviours have been associated with safety outcomes 
such as increased safety climate (Clarke 2013; Zohar 2002) and safety participatory behaviours (Clarke 2013; Clarke and Ward 2006). These studies support the current findings, suggesting that the interactive presence of managers in the field is important in terms of obtaining safety feedback from the various employees in the sharp-end.

Moreover, findings also suggest management's involvement in the field is central for maintaining operational oversight through the supervision and coordination of operational activity. In this regard, increasing the administrative workload of managers is a concern because it shortens the time managers spend at the sharp-end. Increased bureaucratization of safety in the petroleum industry has been problematized in other safety writings (Kongsvik and Fenstad 2007; Wold and Laumann 2015). More paperwork does not necessarily result in better safety, but may, on the contrary, have negative effects by reducing interaction with employees and operational activity supervision. This can impact the ability of managers to build trust relationships with sharp-end employees, at the same time as having detrimental effects on operational oversight, which may increase the risk of major accidents (Reason 1997). In this regard, practitioners should be more aware of the potential safety functions embedded in the interactive role of managers at the sharp-end.

The findings from the present study indicate that long-term organizational relationships between companies may be beneficial for operational safety due to higher levels of stability. This can be seen in the light of other research, showing that long-term interorganizational relationships benefit performance (Ganesan 1994; Noordeweier et al. 1990), lead to better cooperation among companies (Anderson and Weitz 1989) and are a central component of collective learning in organizational systems (Larsson et al. 1998). In this regard, operator companies should, as much as possible, strive to establish long-term contracts, particularly with third-party service companies that are heavily involved in the operation. On the other hand, increased stability due to long-term organizational relationships may also potentially involve increased risk of complacency. If collaborating companies become too settled in their ways of doings things, they may 'forget to be afraid' adopting organizational practices through which important safety signals can be missed or trivialized (Reason 1997; Vaughan 1997). Developing a questioning culture in which diverse viewpoints and critical questions are welcomed and encouraged becomes crucial in this respect to overcome complacency (Weick and Sutcliffe 2007, 2015).

While promoting high-quality work relations may potentially reduce some of the issues related to interorganizational complexity, the involvement of multiple companies still implies certain structural challenges. Coordinating processes and learning from experience prove more challenging when multiple companies are involved. Similar issues are reported in a study of interorganizational clinical handovers in a hospital, where practitioners were found to increase their coordinational efforts in order to manage conflicting priorities (Sujan et al. 2015). Also, the temporal status and variations found among certain groups of sub-contractor employees complicate safety management. In spite of being viewed as mainly operational challenges by informants, such issues may actually increase the risk of major accidents due to the increased likelihood of latent conditions developing in the system (Milch and Laumann 2016; Reason 1997).

In general, there seems to be little awareness among managers and employees about interorganizational aspects of the work, both in terms of challenges as well as how interorganizational complexity influences work overall. Consequently, there is a need for increased awareness around such challenges in the industry. Findings from this study suggest a need for improved systems for coordination of operational processes among companies. In the petroleum industry, initiatives aimed at standardizing safety rules and procedures across companies could be a first step towards reducing complexities caused by company variations, which can make it easier for employees with short-term operational involvement to become familiarized with safety systems.

Moreover, collective learning arenas such as 'Working together for safety' and 'Safety forum' may be particularly important in terms of sharing best practices and experiences across collaborating companies. Parallels can be drawn to the concept communities of practice, which refers to groups of experts, either from different departments or from different companies, that organize informally to cooperate on areas of common interest (Wenger and Snyder 2000). Communities of practice have been found to share knowledge and facilitate transfers of experience and of best practice, and have been linked to increased innovation, improved organizational performance and better problem-solving.

\subsection{Methodological considerations and limitations}

There are certain methodological matters in the current study that need to be addressed. Due to the explorative nature of this study, and the sparsity of existing research in this area, caution should be exercised in terms of drawing firm conclusions from the current findings. More research is needed to further explore influences of interorganizational complexity on safety within other interorganizational safetycritical contexts.

With regard to the aim of the study, the sample is diverse and serves to illuminate different perspectives across organizations and hierarchical positions, providing in-depth knowledge about factors that influence safety. However, data collection was carried out at the onset of an unexpected downturn in the petroleum industry, which impacted the data collection process and resulted in a smaller sample than was originally planned. As a result, the onshore segment includes only operator company informants. Ideally, the 
representation among companies onshore could have been broader, which obviously represents a limitation to the study; however, we maintain that the sample is diverse enough to illuminate the research question.

With regard to rigour, certain aspects should be discussed. In order to assess the credibility of analysis, performing member checks whereby findings are presented to respondents, is recommended (Lincoln and Guba 2000). As a consequence of the downturn in the industry, all of the respondents had been laid off when data analysis was complete, which made it difficult to complete member checks. Instead, findings were presented to our primary contact in the operator company, who confirmed that the categories corresponded well with his perception. The lack of comprehensive member checks can be regarded as a limitation to the current study. However, taking into consideration the unusual circumstances, one could argue the inclusion of an insider perspective provides at least some degree of verification.

The coding and analysis were performed by one of the authors in this study. This is a potential source of bias. It is commonly recommended that coding should be performed by several coders to achieve inter-coder reliability (Silverman 2006). It should be noted, however, that due to the interpretative nature of qualitative research, the aptness of using reliability as a criteria is heavily debated (Yardley 2000). Particularly with explorative approaches, a central aspect in this debate has been whether or not coders can be expected to produce similar coding. A study by Armstrong et al. (1997) provided only partial support for inter-coder reliability and found that although coders identified similar themes, they organized and labelled them differently. Many advocate that the adherence to systematic and thorough analytical processes, together with providing a high level of transparency, is sufficient to ensure rigour (Elliott et al. 1999; Meyrick 2006; Yardley 2000). Accordingly, we argue that the steps taken to ensure quality and transparency in this study contribute to a satisfactory level of rigour.

There are several methodological strengths to the current study that should also be noted. The process by which data were collected and analysed has been systematic and thorough. Moreover, detailed descriptions of the sampling strategy, the context of study and the analytical procedure, and detailed accounts from interview data, contribute to transparency, enabling the reader to judge the quality of the study and opening up possibilities for replication.

Another point that should be discussed concerns the similarity of perceptions among informants. Applying a purposive sampling strategy, we sought to obtain a broad sample representing different organizational segments and roles in order to obtain diverse viewpoints and perspectives. We did expect larger variations in the perceptions among informants, particularly among those that were not hired in the same company, such as contractor and sub-contractor employees. However, they expressed very similar views on the different topics. This can perhaps be explained by the fact that the informants all came from the same industrial culture, and many had worked together over a longer period of time. Moreover, the majority of employees shared the same national background. In other petroleum contexts in which the work force is more culturally diverse, one can probably expect greater variation in perceptions among employees.

An important question is whether the findings may be generalized to other contexts. Qualitative research focuses on obtaining in-depth knowledge about a phenomenon of interest within its context while capturing the inherent complexity, often concentrating on smaller segments or single cases. In this study, as with qualitative research in general, the contextual factors greatly influence the research findings. In this regard, the relevance of applying the concept of generalizability in qualitative methods has been strongly debated, and several researchers subscribe to transferability as a more appropriate concept when qualitative approaches are applied (Lincoln and Guba 2000; Malterud 2001). Transferability refers to the extent to which research findings may be relevant to other contexts. Arguably, the findings from the current study offer several theoretical contributions that may be transferrable, not only to other petroleum contexts, but also to other safety-critical industries. In particular, findings concerning the role of high-quality work relations as a safety contributing element may be highly relevant in other safety-critical industries with similar interorganizational arrangements.

\section{Conclusion}

The aim of the present study was to gain a better understanding for how interorganizational complexity is managed on a petroleum-producing installation. An explorative qualitative approach was used to examine safety challenges and practices that help manage interorganizational complexity. Findings suggest that the quality of work relations across involved companies can have important implications for safety, illuminating the role of high-quality work relations as a component contributing to shared commitment towards operational goals as well as an open environment for reporting. An important condition seemed to be long-term organizational relationships, providing the stability necessary for high-quality relationships to form. Moreover, the role interactive role of managers appears to have important functions in terms of stimulating shared commitment to operational goals among employees from various companies. Accordingly, the presence of highquality work relations in interorganizational safety-critical systems may be a crucial component in counteracting effects of known interorganizational safety challenges such as distrust and fragmented safety management processes by bringing the companies closer in their focus on operational processes and strengthening operational oversight. 
Theoretically, the current study contributes to extend the HRO framework by highlighting the role of high-quality work relations as an element for achieving mindfulness.

While the analysis sheds light on several factors that appear important for achieving and sustaining safety. The study also finds certain safety challenges. Particularly, coordinating and keeping track of work processes across organizational interfaces represents an omnipresent challenge when multiple companies are involved. A concern in this regard is the increased amount of paperwork for managers, reducing time spent outside in the field can have consequences in terms of reduced operational oversight. Considering similar safety challenges have been associated with the occurrence of severe major accidents, the current study highlights the need for increased awareness concerning such challenges, in the petroleum industry as well as in other safety-critical industries characterized by high interorganizational complexity.

This paper presents a first step in gaining a better understanding of safety challenges that can arise from interorganizational complexity, and practices that may help manage such complexity. In this way, the study provides valuable insight into an unexplored area of research. More research is needed to further explore safety challenges and practices that may contribute to achieve and sustain safety in other contexts within the petroleum industry, as well as in other interorganizational safety-critical industries. Regarding future research, their current study highlights certain areas that should be further explored. There is a need for studies to better understand relational mechanisms in connection to safety in such contexts. Additionally, research should address how high-quality work relations can be achieved in interorganizational safety-critical systems. Finally, future research should address the safety functions of managements role in these contexts.

Acknowledgements The work was supported by the Research Council of Norway (Grant Number 220798). We are thankful to all involved in the petroleum operation who participated in the study and contributed to the data collection.

Open Access This article is distributed under the terms of the Creative Commons Attribution 4.0 International License (http://creativecomm ons.org/licenses/by/4.0/), which permits unrestricted use, distribution, and reproduction in any medium, provided you give appropriate credit to the original author(s) and the source, provide a link to the Creative Commons license, and indicate if changes were made.

\section{Appendix 1: Interview guide, rig-company employee (translated from Norwegian)}

\section{Background}

- Work position
- Education

- Work history

- How long have you had this job (how long in current company)?

- Duration of time spent offshore?

- How long have you been offshore this rotation?

\section{Draw organizational map}

(Follow up: who is your manager? do you have management responsibilities? in which case, who are your subordinates?)

Can you describe your previous shift?

- From start to finish

- Was it a typical shift?

- Why/why not?

- If not, what was different?

- What work tasks were completed?

- What kind of equipment do you operate?

- Who were you in contact with during the shift?

- What companies do they come from?

- How does the collaboration work?

- What is the communication like?

- What do you talk about?

- Do you know each other?

- Who did you have lunch with?

In what situations do you cooperate with people from other companies?

- Examples of situations?

- What is the nature of the collaboration?

- What works well?

- What doesn't work?

How do you experience working with people from other companies?

- Compared to working with people from the same company?

- How does it affect the work that employees come from different companies?

- Competence? communication?

- What works well?

- What doesn't work?

- How is the atmosphere between employees from different companies?

- Acquaintance? 
Has there been situations that have been challenging when people come from different companies?

- Do you have examples?

- If yes: what aspects are challenging? management? coordination? information sharing? training/experience? competition? cooperation?

- If yes: was something done to reducing such challenges?

- Describe what

\section{Information and communication}

- How do you get information about work tasks?

- By whom?

- Type of contact? (meeting? phone? etc.)

- Can you describe how this works?

- How do you think it works for you?

- Easy to find relevant information?

- Easy to find procedures?

- What systems do you use?

- Several systems?

- Is it clear what system applies?

- Access to relevant systems?

\section{How are work tasks distributed between companies?}

- Is it clear who is in charge of what?

- Have you ever experienced confusion about who was responsible for what?

- If yes: do you have an example? what was unclear? why? what consequences? consequences for safety?

How do you experience having to relate to the operator as well as your own employer?

How do you relate to the operator company?

- What situations?

- What is the nature of the contact? (direct? indirect?)

- How do you experience talking to coworkers from the operator company?

- How do you experience talking to the safety coach from the operator company?

- Bringing up safety related issues?

Can you describe the drilling operation from start to finish?
- What has happened so far?

- Nature of the operation (typical? non-typical?)

- What has been your role in the operation?

- Has everything gone according to plan?

- If not: why? what happened?

If you see something you think should be reported? What do you do?

- Who do you report to?

- What company?

- Is it clear who to report to?

- What are your thoughts on the ease of reporting?

- What system do you use to report?

- Is it clear what system applies?

\section{Have you ever reported an accident or incident?}

(if yes: can you describe what happened? what kind of incident? who were involved? who did you report to? what happened after? how was the follow up? consequences?)

- Have you ever been in a situation where you chose not to report?

- If yes: what happened? why did you not report? what would have happened if you reported?

Does reporting of incidents and accidents have any consequences?

(follow up: for you? your company? what kind of consequences?)

\section{Recent incidents on the rig}

- Can you describe what happened?

- Where you present on the rig when the incidents occurred?

- What was your role?

- Who were involved?

- How were you informed?

- What happened after the incidents?

- What kind of consequences did the incidents have?

Is there anything you would like to add that I have not addressed?

\section{Appendix 2}

See Tables 3, 4 and 5. 


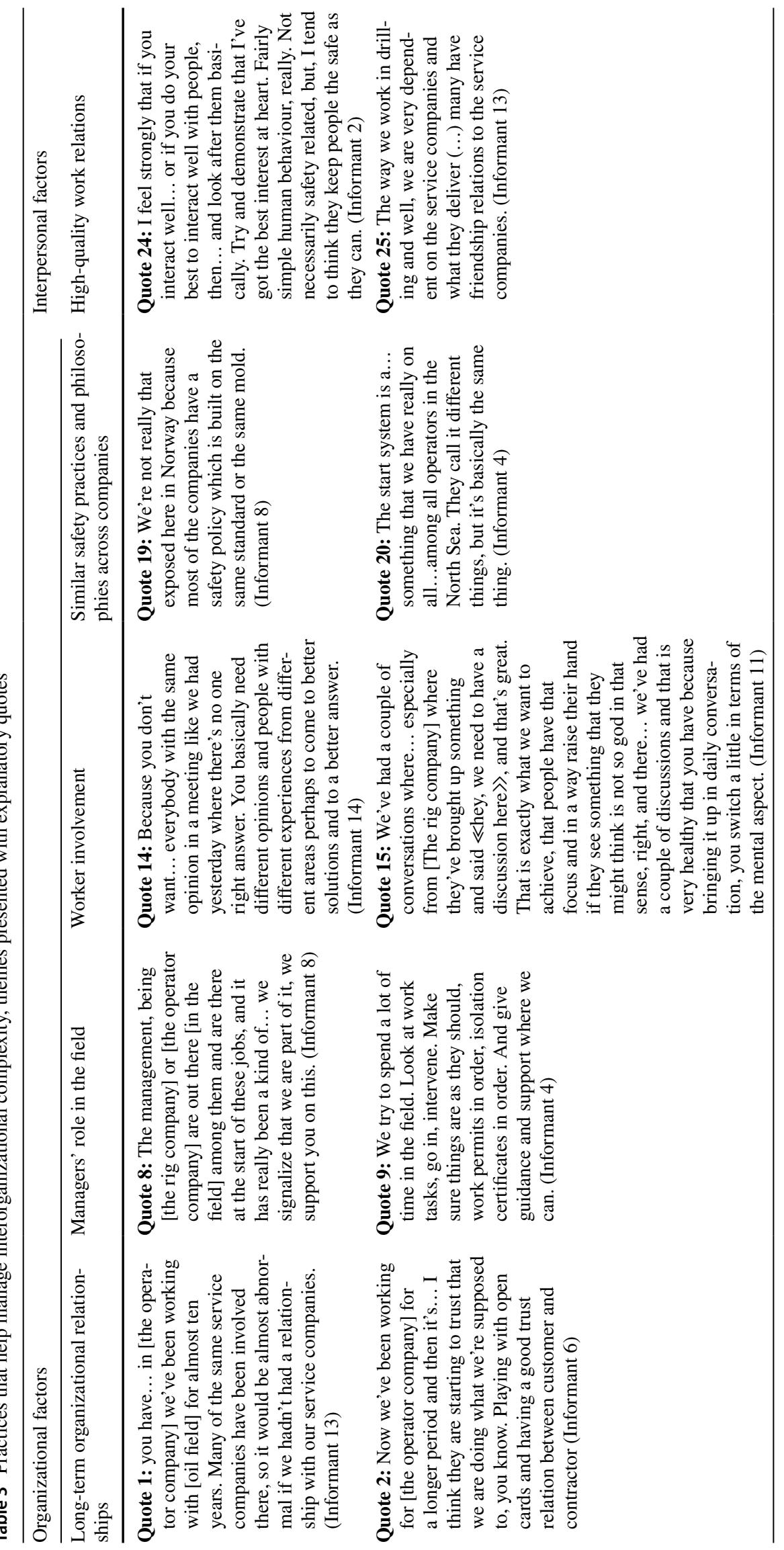




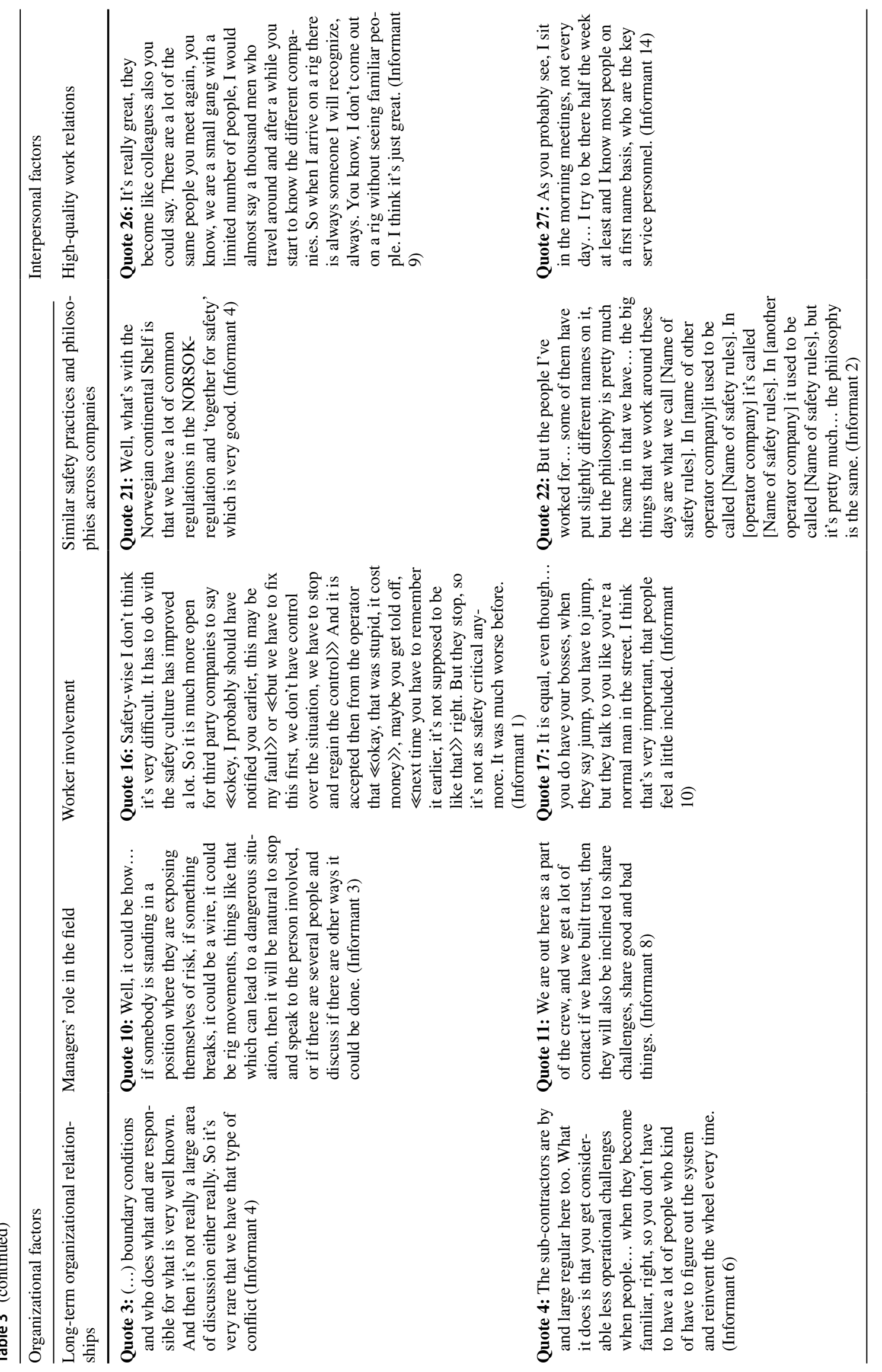




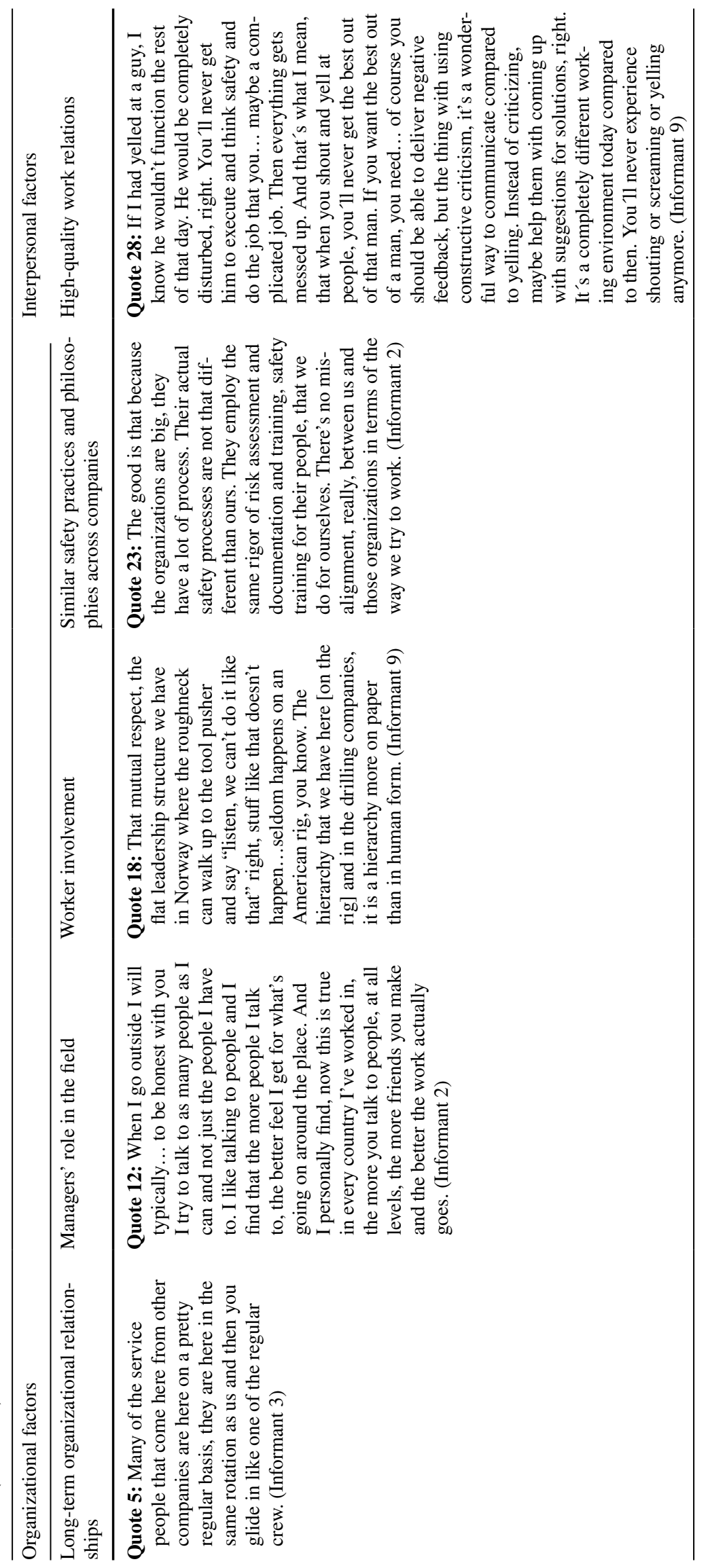




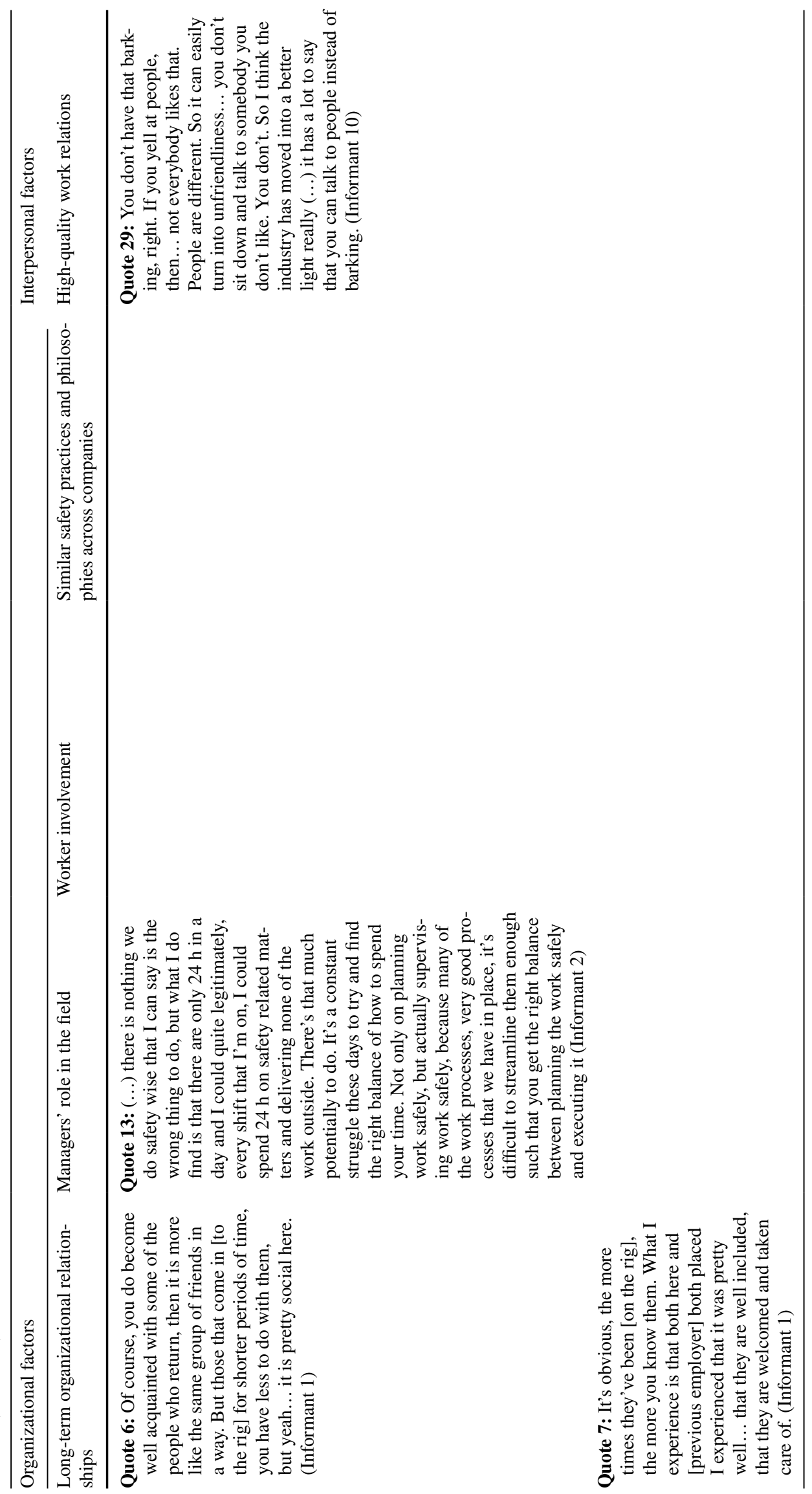


Table 4 Practices that help manage interorganizational complexity, themes presented with explanatory quotes

Behavioural factors

Commitment to mutual operational goals

Reporting

Quote 30: So it's a bit different in terms of much people are involved, but everybody has their function here, so for things to go around, everybody is basically equally dependent on everyone. (Informant 3 )

Quote 31: There are very many who have a small part in many things. There are many service companies that in a way deliver only a tiny part of the well, but are no less important that you include so that you get the risk or that aspect into what you're doing or that decision you're making. (Informant 11)

Quote 32: I don't see it as any big difference working with those sitting in my team compared to the service people. We are working together in delivering a product. (Informant 11)

Quote 33: But these guys who's here, they get that we have a job to do and what we do out here is a teamwork. (informant 8)

Quote 34: Everybody is dependent on each other, particularity in service, where there may be a guy who's sole responsibility is a valve, who's only got the valve, and he's dependent on getting out [on the rig] alone and he's dependent on everybody else in order to cooperate and to know if it fits here or there. And the same with us, we're dependent on having a good collaboration with everyone and be handed the information we need. At the same time, we provide the information they need, so it has to work if we are going to be able to deliver an efficient and good product. (Informant 5)

Quote 35: We work a lot with our greatest competitor (...) and they need information from us and in the same way we need information from them. When we put it into our reporting program, we need inclination on the well, trajectory, how it goes down through, in order for our fluid to... yeah... (...) So there is a lot of information back and forth there. But it works very well. I've never experienced problems there. We all work towards a common goal. (Informant 5)

Quote 36: And that's what so special here, I think, in Norway, it's the fact that we have such good chemistry and that we all work towards the same goals. And that is very important, if we don't, I mean, if we all were to sit in isolated trenches and only look after ourselves, things would go wrong. We have to look ahead and help each other and... «if you do this, things will probably work out much better》》 right, helping each other through... and at least the last 8-10 years it has worked better and better in Norway. (Informant 9)

Quote 37: (...) no matter what one does, it's important to be honest about it straight away... then you often find out what's wrong. (Informant 7)

Quote 38: Well, I don't have anything to gain from keeping things hidden... [operator company] the least so, and the rig company... okay, small things they could probably keep hidden but their interest is that things work. (Informant 9)

Quote 39: No matter if it's a big incident which halts the operation, as long as it's got to do with safety, reporting is appreciated. It's never like it's shoved under the carpet or... it's always appreciated... if there is something, they say that it's good that you report it. (Informant 5)

Quote 40: I've never had any... So... no, it usually works out all right. Honesty lasts longest in this industry and that's... If you find that you've done something without notifying, then it can have real consequences, but if you're honest and say «sorry, I did that 》 you get a pat on the back rather than... And that it the way you have to practice it because it you keep things secret, then it's not... I think it's more positive that you get praised for being honest than being told off. (Informant 10)

Quote 41: You write your name but you can also deliver anonymously, if you want to. But it's very seldom that we get anything anonymous. I have a... we don't use it in a way to... we don't follow up with a disciplinary conversation and that kind of thing because we want an open reporting, so we don't give reprimands if you report something that didn't work out as you had planned. (Informant 4)

Quote 42: That would be in case of hiding something that went wrong, we regard that as much more serious than if you report something that didn't go according to plan. That we encourage. So I think there's no... hope there's no culture for not notifying when something happens. (Informant 4) 
Table 5 Safety challenges, themes illustrated with explanatory quotes

Challenge coordinating work processes across companies

Quote 43: But I think the biggest challenge is ensuring understanding maybe, right. Particularly towards sub-contractors, that we sit on a lot of information and background and history throughout and they come into do a small part of that, that they understand the bigger picture, that is very important. And what influence they have on the big picture, yeah, how they can make a difference. And that is the biggest challenge, that you often can... right, things happen quickly and here... we have all the background information, but it is important to share it so they understand how they fit in and what they can do to make a difference. (Informant 11)

Quote 44: One of the main problems with the contract world is that you take a fairly simple contract we have with a contractor which is not that high risk and does not have a large span, it will still cover approximately 150-200 pages and that is supposed to be followed up, and following up a contract to the letter... I think... that is often the challenge. Both from our side and from the contractor's side. Those contracts are extremely detailed on what should be done and, yeah... best intentions but it's... it has to be followed up, so that's the problem. (Informant 13)

Quote 45: If we are running some sort of tool... picking up for example, there are certain sequences that have to be done right in order to get it right, that part has to go on top of that and to lift that in, we have to do this... Things like these can often disappear in the vastness [of information], and then one spend a lot of time reinventing the wheel, when you are doing it because one does not have the experiences from previously to be able to see it, right. So documenting what we call after action review and get it in the next program is a big job. (...) and this is also challenging because if these companies have a problem out here or some challenge they have to solve, where they see that okay, what was originally written, in that way did not work because this and that, then it's important that they get it into their companies so that they... we learn something from it. So there are definitely challenges connected to this in order to get further. (Informant 8)

Quote 46: A challenge is that the different companies both [rig company] and in this case [operator company] have their own set of rules in addition that often stretches further and partly also are in conflict which makes it challenging for us (...) It leads to inaccuracies and different practices. Work permit systems for example, there you have a NORKSOK-regulatory system which now is combined with what we have in [rig company] internationally and that have made it more complex than what it has to be. So having, what should I say, company internal rules that extent beyond what is agreed upon in NORSOK and 'Together for safety' makes it complicated. It is difficult for people to know what applies and especially these service companies which travel from installation to installation and between different operators have problems seeing what applies, and have to familiarize each time they arrive at a new location. So that's a challenge. (Informant 4)
Varying experience among sub-contractors

Quote 47: Of course, more actors demand more of the cooperation. At least when a lot of actors tend to come and go. Another challenge that we have seen is that... well, I would really say that up until now the activity has been very high. As such, there has been slightly varying quality and level of knowledge in some of the sub-contractors, that personnel. They tend to have... right, they have limited experience. So that has been a challenge that we have had to focus on and have had to follow them up a lot closer so that the primary control over the well is sustained to put it like that, that it is sustained. So that has been a challenge. (Informant 3 )

Quote 48: One does see perhaps... at least I have experienced from a previous rig that the rig crew have been better then third party because the rig crew is on location and get the input and they might perhaps get the training and the safety coach has for example prevention of dropped objects training, and that you have observation technique, but if you're from third party and you haven't been on the rig before, and you might not know what you should focus on... (Informant 12)

Quote 49: And then there is... there have been some challenges with people who are not familiar with the oil industry at times, with the safety focus we have, with sustaining barriers offshore, sending out someone who is... it is not a nice word but... green. You know, that they are very fresh. We have this competence requirement. We want our critical service companies to... before they send out new personnel, who may not have been... if they have not been on the rig before or for us before, then we want them to fill out a competence sheet, and that is about what experience they have and the type of jobs before, and if they are aware of procedures and if they are aware of risks, and in that case which, what they do if they come across something. (Informant 11)

\section{References}

Anderson E, Weitz B (1989) Determinants of continuity in conventional industrial channel dyads. Mark Sci 8:310-323

Armstrong D, Gosling A, Weinman J, Marteau T (1997) The place of inter-rater reliability in qualitative research: an empirical study. Sociology 31:598-606. https://doi.org/10.1177/003803859703 1003015
Bass BM (1985) Leadership and performance beyond expectations. The Free Press, New York

Beale CJ (2003) Factors influencing the safe management of contractors on major hazard installations. Paper presented at the IchemM Hazards XVII, Manchester, March 25-27

Braun V, Clarke V (2006) Using thematic analysis in psychology. Qual Res Psychol 3:77-101 
Carmeli A, Gittell JH (2009) High-quality relationships, psychological safety, and learning from failures in work organizations. J Organ Behav 30:709-729. https://doi.org/10.1002/job.565

Cedergren A (2013) Implementing recommendations from accident investigations: a case study of inter-organisational challenges. Accid Anal Prev 53:133-141. https://doi.org/10.1016/j.aap.2013 .01 .010

Clarke S (2003) The contemporary workforce. Implications for organisational safety culture. Pers Rev 32:40-57. https://doi.org/10.1108 /00483480310454718

Clarke S (2013) Safety leadership: a meta-analytic review of transformational and transactional leadership styles as antecedents of safety behaviours. J Occup Organ Psychol 86:22-49. https://doi. org/10.1111/j.2044-8325.2012.02064.x

Clarke S, Ward K (2006) The role of leader influence tactics and safety climate in engaging employees' safety participation. Risk Anal 26:1175-1185. https://doi.org/10.1111/j.1539-6924.2006.00824.x

Collinson DL (1999) Surviving the rigs': safety and surveillance on North Sea oil installations. Organ Stud 20:579-600. https://doi. org/10.1177/0170840699204003

Conchie SM, Donald IJ (2008) The function and development of safety-specific trust and distrust. Saf Sci 46:92-103. https://doi. org/10.1016/j.ssci.2007.03.004

Corbin J, Strauss A (2014) Basics of qualitative research: techniques and procedures for developing grounded theory. Sage Publications, Thousand Oaks

Creswell JW, Miller DL (2010) Determining validity in qualitative inquiry. Theory Pract 39:124-130. https://doi.org/10.1207/s154 30421tip3903_2

Dekker S (2012) Drift into failure: from hunting broken components to understanding complex systems. Ashgate Publishing Limited, Farnham

Edmondson AC, Lei Z (2014) Psychological safety: the history, renaissance, and future of an interpersonal construct. Annu Rev Organ Psychol Organ Behav 1:23-43. https://doi.org/10.1146/ annurev-orgpsych-031413-091305

Elliott R, Fischer CT, Rennie DL (1999) Evolving guidelines for publication of qualitative research studies in psychology and related fields. Br J Clin Psychol 38:215-229

Flin R, Yule S (2004) Leadership for safety: industrial experience. Qual Saf Health Care 13:45-51. https://doi.org/10.1136/qshc .2003 .009555

Ganesan S (1994) Determinants of long-term orientation in buyerseller relationships. J Mark 58:1-19. https://doi.org/10.2307 $/ 1252265$

Garner JT (2006) Masters of the universe? Resource dependency and interorganizational power relationships at NASA. J Appl Commun Res 34:368-385. https://doi.org/10.1080/00909880 600911249

Gomes JO, Woods DD, Carvalho PVR, Huber GJ, Borges MRS (2009) Resilience and brittleness in the offshore helicopter transportation system: the identification of constraints and sacrifice decisions in pilots' work. Reliab Eng Syst Saf 94:311-319. https:// doi.org/10.1016/j.ress.2008.03.026

Grøtan TO, Albrechtsen E, Rosness R, Bjærkebæk E (2010) The influence on organizational accident risk by integrated operations in the petroleum industry. Saf Sci Monit 14:1-11

Guba EG, Lincoln YS (1994) Competing paradigms in qualitative research. In: Denzin NK, Lincoln YS (eds) Handbook of qualitative research, 2nd edn. Sage Publications, Thousand Oaks

Hart SM (2002) Norwegian workforce involvement in safety offshore: regulatory framework and participants' perspectives. Empl Relat 24:486-499. https://doi.org/10.1108/01425450210443267

HM Railway Inspectorate (1999) Railway accident at Bexley. A report on the investigation into the derailment of a freight train at Bexely on the Daryford Loop line of Railtrack Southern Zone on 4 February 1997. HM Railway Inspectorate, Norwich

Hofmann DA, Morgeson FP (1999) Safety-related behavior as a social exchange: the role of perceived organizational support and leader-member exchange. Appl Psychol 84:286-296. https://doi. org/10.1037/0021-9010.84.2.286

Hollnagel E (2012) Coping with complexity: past, present and future. Cogn Technol Work 14:199-205. https://doi.org/10.1007/s101 11-011-0202-7

Hollnagel E (2014) Safety-1 and safety-2: the past and future of safety management. Ashgate Publishing Limited, Farnham

Hollnagel E, Cacciabue PC (1999) Cognition, technology and work: an introduction. Cogn Technol Work 1:1-6. https://doi.org/10.1007 /s101110050006

Hopkins A (2007) The problem of defining high reliability organisations. Working paper 51, The Australian National University, Canberra, The National Research Centre for Occupational Health and Safety Regulations

Hopkins A (2014) Issues in safety science. Saf Sci 67:6-14. https://doi. org/10.1016/j.ssci.2013.01.007

Jeffcott S, Pidgeon N, Weyman A, Walls J (2006) Risk, trust and safety culture in U.K. train operating companies. Risk Anal 26:11051121. https://doi.org/10.1111/j.1539-6924.2006.00819.x

Johnsen SO, Vatn J, Rosness R, Herrera IA (2006) Cross border railway operations: improving safety at cultural interfaces. Cogn Technol Work 1:76-88. https://doi.org/10.1007/s10111-005-0022-8

Kirwan B (2001) Coping with accelerating socio-technical systems. Saf Sci 37:77-107. https://doi.org/10.1016/S0925-7535(00)000-44-8

Kivimäki M, Kalimo R, Salminen S (1995) Perceived nuclear risk, organizational commitment and appraisals of management: a study of nuclear power personnel. Risk Anal 26:1105-1121. http s://doi.org/10.1111/j.1539-6924.1995.tb00331.x

Kongsvik T, Fenstad JS (2007) Organizational interfaces, resilience and safety: a case study from the petroleum industry in Norway. In: Aven T, Vinnem J-E (eds) Risk, reliability and societal safety, vol 3. Taylor and Francis Group, London, pp 2457-2463

Kontogiannis T (2010) A contemporary view of organizational safety: variability and interactions of organizational processes. Cogn Technol Work 12:231-249. https://doi.org/10.1007/s10111-0091031-x

Kvale S (2008) Doing interviews. Sage Publications, London

La Porte TR, Roberts KH (1998) The self-designing high-reliability organization: aircraft carrier flight operations at sea. Nav War Coll Rev 51:97-113

Larsson R, Bengtsson L, Henriksson K, Sparks J (1998) The interorganizational learning dilemma: collective knowledge development in strategic alliances. Organ Sci 9:285-305. https://doi. org/10.1287/orsc.9.3.285

Le Coze J-C (2005) Are organizations too complex to be integrated in technical risk assessment and current safety auditing? Saf Sci 43:613-638. https://doi.org/10.1016/j.ssci.2005.06.005

Leveson N (2011) Complexity and safety. In: Hammami O, Krob D, Voirin J-L (eds) Complex systems design and management. Springer, Paris, pp 27-39

Lincoln YS, Guba EG (2000) Pragmatic controversies, contradictions and emerging confluences. In: Dechy N, Lincoln YS (eds) Handbook of qualitative research, 2nd edn. Sage Publications, Los Angeles, pp 97-128

Malterud K (2001) Qualitative research: standards, challenges and guidelines. The Lancet 358:483-488. https://doi.org/10.1016/ S0140-6736(01)05627-6

Mayhew C, Quinlan M, Ferris R (1997) The effects of subcontracting/ outsourcing on occupational health and safety: survey evidence from four Australian industries. Saf Sci 25:163-178. https://doi. org/10.1016/S0925-7535(97)00014-3 
Mearns KJ, Reader T (2008) Organizational support and safety outcomes: an un-investigated relationship? Saf Sci 46:388-397. http s://doi.org/10.1016/j.ssci.2007.05.002

Meyrick J (2006) What is good qualitative research? A first step towards a comprehensive approach to judging rigour/quality. J Health Psychol 11:799-808. https://doi.org/10.1177/13591053 06066643

Milch V, Laumann K (2016) Interorganizational complexity and organizational accident risk: a literature review. Saf Sci 82:9-17. http s://doi.org/10.1016/j.ssci.2015.08.010

Ministry of Labour and Social Inclusion (2005) Helse, miljø og sikkerhet i petroleumsvirksomheten (St.mld.nr 12, 2005-2006). http s://www.regjeringen.no/no/dokumenter/stmeld-nr-12-2005-2006 -/id408103/. Accessed 27 May 2017

Montara Commission of Inquiry (2010) Report of the Montara Commission of Inquiry, Canberra, Montara Commission of Inquiry

Nævestad TO, Olsen E, Haukelid K (2007) The effect of a safety program on informal hierarchies and care among workers within oil and gas. In: Aven T, Vinnem J-E (eds) Risk, Reliability and Societal Safety, Application Topics 3. Taylor and Francis Group, London, pp 2495-2502

National Commission on the BP Deepwater Horizon Oil Spill and Offshore Drilling (2011) Macondo: the gulf oil disaster. Chief Councel's report, National Commission on the BP Deepwater Horizon Oil Spill and Offshore Drilling. http://www.oilspillcomm ission.gov/sites/default/files/documents/C21462-408_CCR_for_ web_0.pdf. Accessed 15 Aug 2015

Noordeweier TG, John G, Nevin JR (1990) Performance outcomes of purchasing arrangements in industrial buyer-vendor relationships. J Mark 54:80-94. https://doi.org/10.2307/1251761

Office of Rail Regulation (2006) Train derailment at Hatfield: a final report by the independent investigation board. Office of Rail Regulations, London

Patton MQ (2014) Qualitative research and evaluation methods: integrating theory and practice. Sage Publications Limited, Los Angeles

Perrow C (1984) Normal accidents: living with high risk systems. Princeton University Press, Princeton

Rasmussen J (1997) Risk management in a dynamic society: a modelling problem. Saf Sci 27:183-213

Rasmussen J, Svedung I (2000) Proactive risk management in a dynamic society. Swedish Rescue Services Agency, Karlstad

Reason J (1997) Managing the risks of organizational accidents. Ashgate Publishing Company, Hampshire

Roberts KH (1990) Some characteristics of one type of high reliability organization. Organ Sci 1:160-176

Roberts KH, Rousseau DM (1989) Research in nearly failure-free, high-reliability organizations: having the bubble. IEEE Trans Eng Manag 36:132-139

Roberts KH, Rousseau DM, La Porte TR (1994) The culture of high reliability: quantitative and qualitative assessment aboard nuclearpowered aircraft carriers. J High Technol Manag Res 5:141-161. https://doi.org/10.1016/1047-8310(94)90018-3

Rochlin GI, La Porte TR, Roberts KH (1998) The self-designing highreliability organization: aircraft carrier flight operations at sea. Nav War Coll Rev 51:97
Schulman PR (1993) The negotiated order of organizational reliability. Adm Soc 25:353-372

Silverman D (2006) Interpreting qualitative data. Sage Publications Limited, London

Standard Norge (2017) NORSOK standards. https://www.standard.no/ en/sectors/energi-og-klima/petroleum/norsok-standards/\#.WQrM 0-WGNaR. Accessed 14 May 2017

Sujan MA (2015) An organisation without a memory: a qualitative study of hospital staff perceptions on reporting and organisational learning for patient safety. Reliab Eng Syst Saf 144:45-52. https:// doi.org/10.1016/j.ress.2015.07.011

Sujan MA, Chessum P, Rudd M, Fitton L, Inada-Kim M, Cooke MW, Spurgeon $\mathrm{P}$ (2015) Managing competing organizational priorities in clinical handover across organizational boundaries. J Health Serv Res 25:17-25. https://doi.org/10.1117/1355819614560449

Tharaldsen JE (2011) 'In safety we trust': Safety risk and trust in the offshore petroleum industry. Dissertation, University of Stavanger

Tinmannsvik RK et al (2011) Deepwater Horizon-ulykken: Årsaker, lærepunkter og forbedringstiltak for norsk sokkel. SINTEF Teknologi og samfunn, Trondheim

Turner B (1978) Man-Made disasters. Wykeham Science Press, London

Vaughan D (1990) Autonomy, interdependence, and social control: NASA and the space shuttle Challenger. Adm Sci Q 35:225-257

Vaughan D (1997) The Challenger launch decision: risky technology, culture, and deviance at NASA. University of Chicago Press, Chicago

Vogus TJ, Rothman NB, Sutcliffe KM, Weick KE (2014) The affective foundations of high-reliability organizing. J Organ Behav 35:592-596. https://doi.org/10.1002/job.1922

Weick KE (1987) Organizational culture as a source of high reliability. Calif Manag Rev 29:112-127

Weick KE (1993) The collapse of sensemaking in organizations: the Mann Gulch disaster. Adm Sci Q 38:628-652. https://doi. org/10.2307/2393339

Weick KE, Roberts KH (1993) Collective mind in organizations: heedful interrelating on flight decks. Adm Sci Q 38:357-381

Weick KE, Sutcliffe KM (2007) Managing the unexpected: resilient performance in an age of uncertainty. Wiley, San Francisco

Weick KE, Sutcliffe KM (2015) Managing the unexpected: sustained performance in a complex world. Wiley, San Francisco

Weick KE, Sutcliffe KM, Obstfeld D (2008) Organizing for high reliability: processes of collective mindfulness. Crisis Manag 3:81-123

Wenger EC, Snyder WM (2000) Communities of practice: the organizational frontier. Harvard Bus Rev 78:139-145

Wold T, Laumann K (2015) Safety management systems as communication in an oil and gas producing company. Saf Sci 72:23-30. https://doi.org/10.1016/j.ssci.2014.08.004

Yardley L (2000) Dilemmas in qualitative health research. Psychol Health 15:215-228. https://doi.org/10.1080/08870440008400302

Zohar D (2002) The effects of leadership dimensions, safety climate, and assigned priorities on minor injuries in work groups. J Organ Behav 23:75-92. https://doi.org/10.1002/job.130 